OPEN ACCESS

Edited by:

Chen Huang,

Chinese Academy of Forestry, China

Reviewed by:

Chunbao (Charles) Xu,

Western University, Canada

Caoxing Huang,

Nanjing Forestry University, China

Bailiang Xue,

Shaanxi University of Technology,

China

*Correspondence:

Brita Asikanius

brita.asikanius@aalto.fi

Monika Österberg

monika.osterberg@aalto.fi

Specialty section:

This article was submitted to

Bioenergy and Biofuels,

a section of the journal

Frontiers in Energy Research

Received: 24 September 2021

Accepted: 03 November 2021

Published: 25 November 2021

Citation:

Asikanius $B$, Jääskeläinen A-S, Koivula H, Oinonen P and Österberg $M$ (2021) Durable Biopolymer Films From Lignin-Carbohydrate Complex Derived

From a Pulp Mill Side Stream.

Front. Energy Res. 9:782545.

doi: 10.3389/fenrg.2021.782545

\section{Durable Biopolymer Films From Lignin-Carbohydrate Complex Derived From a Pulp Mill Side Stream}

\author{
Brita Asikanius ${ }^{1,2 *}$, Anna-Stiina Jääskeläinen ${ }^{2}$, Hanna Koivula ${ }^{3}$, Petri Oinonen ${ }^{4}$ and \\ Monika Österberg ${ }^{1 *}$
}

${ }^{1}$ Department of Bioproducts and Biosystems, Aalto University, Espoo, Finland, ${ }^{2}$ Research and Development Center, Kemira Oyj, Espoo, Finland, ${ }^{3}$ Department of Food and Nutrition and Helsinki Institute of Sustainability Science, University of Helsinki, Helsinki, Finland, ${ }^{4}$ Ecohelix $A B$, Stockholm, Sweden

Valorization of side streams offers novel types of raw materials to complement or replace synthetic and food-based alternatives in materials science, increasing profitability and decreasing the environmental impacts of biorefineries. Lignocellulose biomass contains lignin and carbohydrates that are covalently linked into lignin-carbohydrate complexes (LCCS). In biomass fractionation processes, these complexes are conventionally considered as waste, which hinders the biomass fractionation process, and they may solubilize into aqueous effluents. This study presents how LCCs, derived from pulp mill effluent, can be turned into valuable biopolymers for industrial polymer film applications. Free-standing composite films containing hydroxyethyl cellulose (HEC) and LCCs with varying molar mass, charge density and lignin/hemicellulose ratio were prepared to study the effect of LCC amount on mechanical properties and oxygen permeability. Increasing the LCC content increased the yield point and Young's modulus of the films. Breaking strain measurements revealed a non-linear correlation with the LCC concentration for the samples with higher lignin than hemicellulose content. The addition of LCC enhanced oxygen barrier properties of HEC films significantly even at high relative humidity. The present research demonstrates how a currently underutilized fraction of the biorefinery side stream has the potential to be valorized as a biopolymer in industrial applications, for example as a barrier film for paper and board packaging.

Keywords: lignin-carbohydrate complex, LCC, biopolymer film, lignocellulose biomass, side stream valorization, mechanical properties, oxygen barrier

\section{INTRODUCTION}

Lignin-carbohydrate complexes (LCCs) are biopolymers consisting of covalently bound lignin and carbohydrate moieties. They are formed during the biosynthesis of plant cell walls, and their function in natural systems is to enhance the mechanical strength of plants (Zhang et al., 2020). It is estimated that all lignin fragments in softwood and $47-66 \%$ of the lignin in hardwood are bound with carbohydrate moieties, mostly hemicellulose (Lawoko et al., 2005; Henriksson et al., 2007). The chemical structures of LCCs vary depending on the wood source and type of the refinery process. Therefore, their chemical and physical properties are not well understood (Zhao et al., 2020). The covalent bonds between lignin and carbohydrate moieties have been studied by ${ }^{1} \mathrm{H},{ }^{13} \mathrm{C}$ and $2 \mathrm{D}$ NMR spectroscopies, and the main linkages identified are phenyl 
glycoside, acetal, ester and benzyl ether bonds (Balakshin et al., 2011; Giummarella et al., 2019; Pei et al., 2020; Zhao et al., 2020).

In a biomass fractionation process, the aim is to separate cellulose, lignin and hemicellulose. However, the stable covalent bonds between lignin and carbohydrate moieties reduce the selective fractionation of the wood components and hinder the delignification processes, restricting the efficient use of biomass (Balakshin et al., 2011; Yuan et al., 2012; Giummarella et al., 2019; Carvalho et al., 2020; Zhao et al., 2020). The fraction containing LCCs is typically considered to have minor value and therefore ends up in the process side stream. The majority of biorefinery side streams are currently used in low-value applications, for example as combustible material, or treated as waste (Strassberger et al., 2014; Abbadessa et al., 2018; Giummarella et al., 2019). Some challenges hindering the efficient use of the biorefinery side streams are, for example, the low technology readiness level for efficient recovery, the varying chemical structure of the components and the competition from cheaper fossil-based alternatives with well-known chemical characteristics in applications. Enabling the use of new types of raw materials derived from such side streams would require developing novel extraction technologies which in turn may lead to the need for investments to modify the host process.

Finding valuable uses for biorefinery side streams is a significant factor in optimizing the use of biomass. Valorizing the currently unexploited fraction in second-generation biorefineries is expected to increase the process profitability and to have a positive impact on the carbon footprint of the process plants (Steinmentz et al., 2019; Wu et al., 2020). Aiming for zero-waste production is an ambitious goal for biorefineries seeking to develop a more sustainable bioeconomy. However, it is well aligned with the climate change targets of the United Nation's Sustainable Development Goals. Efficient valorization of process side streams could reduce the amount of waste produced at the mill. As an example, we have calculated that for a pulp mill with a 200000 -ton yearly production rate it is possible to reduce the amount of organic waste by 20000 -ton and turn that side stream into valuable biopolymers. To be able to valorize the process effluents, deeper insights into the chemical composition of the produced side streams are required and efficient approaches for their application in materials are needed.

While the structure of various LCCs has been extensively studied (Balakshin et al., 2011; Giummarella et al., 2019; Pei et al., 2020; Zhao et al., 2020), the potential of LCCs in applications is less explored. Dong et al. (2020) reported on the advantage of the oxygen scavenging ability of LCCs in biomedical applications, while (Rivière et al., 2020) suggested that the carbohydrate rich residue from biorefineries could be used in nanocomposites together with cellulose nanofibrils, but in that case the LCCs had a detrimental effect on both mechanical properties and oxygen permeability. The aim of this study is to show examples of how a currently underutilized LCC from a specific biorefinery side stream could be converted into a valuable biopolymer. The experiments were performed at laboratory scale, but the LCC production is aiming to reach technology readiness level 7 meaning that the production will be demonstrated at industrially relevant scale. The feedstock originates from a dissolving pulp mill with a sulphite cooking process using a prehydrolysis step to remove LCC and other impurities from the cellulose fraction. Some of the prehydrolysis liquor is circulated back into the process but most of it is treated as waste. The LCC was derived from this side stream and modified enzymatically by Ecohelix technology (Oinonen 2014). The polymer studied in this work is water soluble and anionically charged. The work demonstrates the potential of the LCC to be valorized in polymeric film applications.

As an example, composite films with LCC, hydroxyethyl cellulose and glycerol were produced. The effect of LCC amount, molecular weight and lignin/hemicelluose ratio on mechanical properties is shown and compared to the behavior of lignosulphonate. Increased LCC content is observed to enhance durability. The oxygen barrier was selected as an example application for polymeric films in paper and packaging application. It is shown that LCC decreases the oxygen transmission rate significantly at various humidity levels.

\section{MATERIALS AND METHODS}

\section{Materials}

The LCC studied in this work was produced by Ecohelix technology (Oinonen et al., 2013; Oinonen et al., 2015) from the side stream of the Domsjö Fabriker dissolving pulp mill and polymerized by laccase treatment using Ecohelix technology (Henriksson et al., 2012). The Ecohelix process (Figure 1) is based on membrane filtration and enzymatic treatment working in unison. The first membrane filtration unit was used to concentrate the desired molecules in the pre-hydrolysis liquor and to return cooking liquors and undesired organic molecules back to the host process. The consecutive enzymatic treatment phase utilized a redox enzyme laccase for the chain extension of molecules containing reactive phenolic moieties, such as noncondensed guaiacyl units in the LCC. The last phase of the process utilized another membrane filtration process to refine and control the molecular weight of the polymeric product and to separate the sugar fraction that contained the unreacted molecules. The produced lignin-carbohydrate complex consisted of alternating lignin and polysaccharide segments, providing an amphiphilic structure. It was negatively charged due to the sulfonic acid groups on the lignin, and carboxyl groups on the polysaccharide moieties.

The specific LCC used here, LCC $80 / 20$, was an aqueous solution with approximately $20 \mathrm{w}$ - $\%$ solids content. LCC $80 / 20$ was compared to three other polymers: LCC 80/20 high molecular weight (HMW), LCC 40/60, and lignosulphonate. LCC $80 / 20$ HMW was derived from the same feedstock as LCC $80 / 20$ but polymerized for longer time to reach a higher degree of polymerization. LCC 40/60 was derived from a thermomechanical pulping process (TMP) and had a larger hemicellulose fraction compared to LCC 80/20. The final reference was lignosulphonate from Domsjö Fabriker AB. All samples were provided by Ecohelix AB. Free-standing films were formed as composites with hydroxyethyl cellulose (HEC) having 


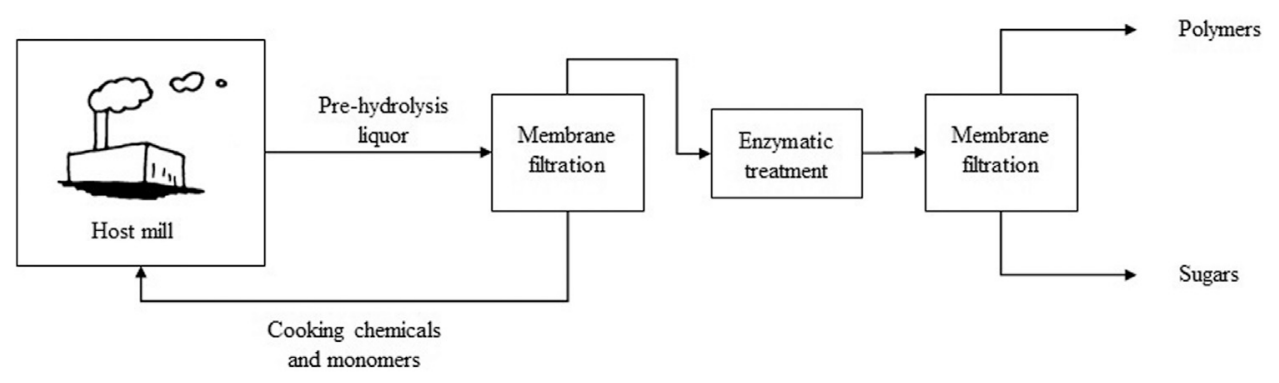

FIGURE 1 | Schematic description of the Ecohelix process for LCC production.

a viscosity based molar mass of $90 \mathrm{kDa}$ on average. Glycerol was used as a plasticizer. HEC and glycerol were purchased from Sigma Aldrich, United States.

\section{Lignin and Carbohydrate Content}

The lignin content of LCC $80 / 20$ was quantified by UV spectroscopy at $280 \mathrm{~nm}$ wavelength using absorptivity of $11.9 \mathrm{~g}^{-1} \mathrm{~cm}^{-1}$, reported previously for lignosulphonate (Lin 1992). The carbohydrate content was analyzed after acid methanolysis and silylation by gas chromatography equipped with a flame ionization detector (GC FID) (Sundberg et al., 2007; Wang et al., 2020).

\section{Molar Mass}

The weight average molar masses of LCC 80/20, LCC 80/20 HMW, LCC 40/60, and lignosulphonate were determined by size-exclusion chromatography (SEC) using Viscotek GPCmax TDA 302 SEC equipment with refractive index detection. The eluent was $0.1 \mathrm{M} \mathrm{NaNO}_{3}$ in MilliQ-water with $2.5 \mathrm{v}-\%$ acetonitrile, and a flow rate of $0.8 \mathrm{ml} / \mathrm{min}$ in $35^{\circ} \mathrm{C}$ was used. The column set consisted of three columns (Waters Ultrahydrogel 2000, 500 and 120) and a guard column. The injection volume was $50 \mu \mathrm{L}$. The quantification was performed using pullulan calibration standards with molar masses between 342 and $708000 \mathrm{Da}$ purchased from Polymer Standard Service, Germany.

\section{Charge Density}

To quantify the charge densities, the polymers were titrated with cationic PDADMAC (polydiallyl dimethyl ammonium chloride) (BTG, Germany) having a specific charge of $1 \mathrm{meq} / \mathrm{l}$ and molar mass of $107 \mathrm{kDa}$. The specific charge of the samples was calculated by Eq. 1, where $\mathrm{q}$ is the specific charge (meq/g), c and $\mathrm{V}$ are the concentration (meq/l) and volume (l) of the titrant respectively, and $\mathrm{m}$ is the mass of the studied polyelectrolyte $(\mathrm{g})$.

$$
q=\frac{c V}{m}
$$

\section{Free Standing Films}

In preliminary film formation trials, it was observed that the pure LCC $80 / 20$ produced too fragile films to be handled in the tensile and oxygen transmission tests. Therefore, preparation of composite films with another film forming biopolymer and plasticizer was required. Free-standing films were prepared to an average grammage of $100 \mathrm{~g} / \mathrm{m}^{2}$. Dry composite films contained $5 \mathrm{w}-\%$ glycerol as a plasticizer, $0-50 \mathrm{w}-\%$ LCC or lignosulphonate at $10 \mathrm{w}-\%$ intervals, and $95-45 \mathrm{w}-\%$ HEC. Films were prepared by mixing the components as $2 \mathrm{w}-\%$ water solutions for at least $30 \mathrm{~min}$ prior to solvent evaporation. Prior to mixing the components, HEC was dissolved by magnetic stirring, heating the solution to $80^{\circ} \mathrm{C}$, and filtering with 75 and $20 \mu \mathrm{m}$ sieves before use. LCC 80/20, LCC 80/20 HMW, LCC 40/60, lignosulphonate and glycerol were diluted using magnetic stirring at room temperature and filtered using a $20 \mu \mathrm{m}$ sieve. The films were cast on plastic petri dishes with a $9 \mathrm{~cm}$ diameter, and water was evaporated in a $50^{\circ} \mathrm{C}$ heating chamber for 1 day. The thickness of the films was measured with a Lorentzen and Wettre SE 250 D micrometer by placing the films between two transparencies to avoid mechanical damage to the films.

\section{Mechanical Properties}

Mechanical properties of the composite films containing LCC 80/ 20, LCC 80/20 HMW, LCC 40/60, and lignosulphonate were evaluated by measuring stress-strain curves with a tensile and compression testing machine, MTS 400 (MTS Systems Norden $\mathrm{AB}$, Sweden). The films were cut into slices with $15 \mathrm{~mm}$ width, and three parallel samples were measured. A load cell of $50 \mathrm{~N}$ was used with a pulling rate of $5 \mathrm{~mm} / \mathrm{min}$. Measurements were performed in a climate-controlled laboratory with 50\% humidity and $23^{\circ} \mathrm{C}$ temperature after $2-6 \mathrm{~h}$ climatization before the measurement. The average values of the three samples were used to quantify Young's modulus and breaking strain.

\section{Oxygen Transmission Rate}

The oxygen transmission rate (OTR) for the composite films containing varying amounts of LCC 80/20 was quantified at two different humidity levels, according to the standard test method for oxygen gas transmission rate through plastic film and sheeting using a coulometric sensor (ASTM D 3985-05). The films were measured using a $5 \mathrm{~cm}^{2}$ area and a pressure gradient of $1 \mathrm{~atm}$. The first set of samples was measured with a Systech Oxygen Permeation Analyzer 8001 at $23^{\circ} \mathrm{C}$ and $50 \%$ relative humidity $(\mathrm{RH})$, analyzing four parallel 
TABLE 1 | Lignin/hemicellulose ratio, charge density at pH 6 and apparent molar mass for LCC 80/20, LCC 80/20 HMW, LCC 40/60 and lignosulphonate.

\begin{tabular}{lcr}
\hline Sample & $\begin{array}{c}\text { Lignin (L) + } \\
\text { Hemicellulose (H) }\end{array}$ & $\begin{array}{c}\text { Charge } \\
\text { density (pH 6) }\end{array}$ \\
\hline LCC 80/20 & $790 \mathrm{mg} / \mathrm{g} \mathrm{L}+180 \mathrm{mg} / \mathrm{g} \mathrm{H}$ & $-2.2 \mathrm{meq} / \mathrm{g}$ \\
LCC 80/20 HMW & $800 \mathrm{mg} / \mathrm{g} \mathrm{L}+190 \mathrm{mg} / \mathrm{g} \mathrm{H}$ & $-2.9 \mathrm{meq} / \mathrm{g}$ \\
LCC 40/60 & $430 \mathrm{mg} / \mathrm{g} \mathrm{L}+570 \mathrm{mg} / \mathrm{g} \mathrm{H}$ & $-0.3 \mathrm{meq} / \mathrm{g}$ \\
Lignosulphonate & $1,000 \mathrm{mg} / \mathrm{g} \mathrm{L}$ & $-1.3 \mathrm{meq} / \mathrm{g}$
\end{tabular}

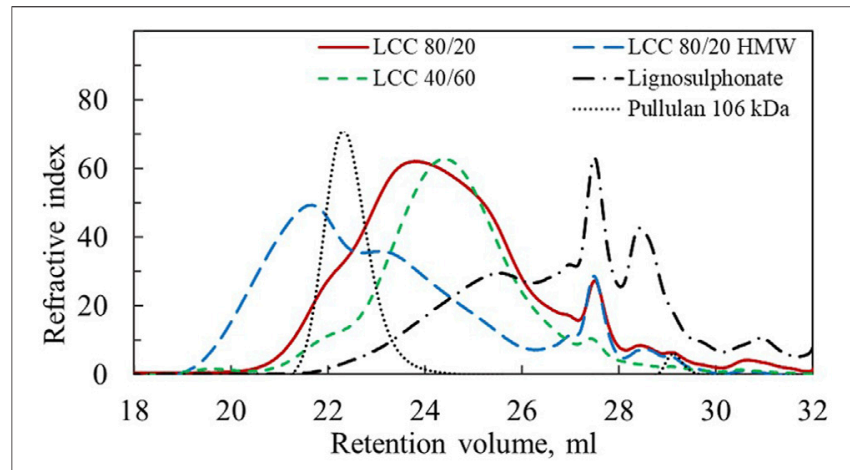

FIGURE 2 | SEC chromatograms for LCC 80/20, LCC 80/20 HMW LCC 40/60, lignosulphonate and pullulan calibration standard with $M_{w}$ $106 \mathrm{kDa}$.

samples of each film containing 0, 10, 20, 30 and $40 \mathrm{w}-\%$ LCC 80/20. Prior to the analysis, the films were stabilized overnight in a climatecontrolled room with constant $50 \%$ humidity and $23^{\circ} \mathrm{C}$ temperature.

The oxygen transmission rate test for the second set of samples was performed with another Systech Oxygen Permeation Analyzer 8001 having the capability to raise the humidity level. This time the experiments were performed at $23^{\circ} \mathrm{C}$ and $80 \% \mathrm{RH}$, again analyzing four parallel samples of each concentration. Prior to the test, the samples were stored for at least $24 \mathrm{~h}$ at $50 \% \mathrm{RH}$ and $23^{\circ} \mathrm{C}$. To ensure that the films were at the desired humidity, they were measured under these conditions at least one day. Before recording the result, the variation in oxygen transmission had to be less than $5 \%$ during the last $20 \%$ of the measuring time.

Oxygen permeability (OP) in $\left(\mathrm{cm}^{3} \mathrm{~mm}\right) /\left(\mathrm{m}^{2}\right.$ day atm) was calculated from the OTR result in $\left(\mathrm{cm}^{3}\right) /\left(\mathrm{m}^{2}\right.$ day) using Eq. 2 where 1 is thickness $(\mathrm{mm})$ of the films and $\Delta \mathrm{P}$ (atm) is the pressure gradient.

$$
\mathrm{OP}=\mathrm{OTR}\left(\frac{l}{\Delta P}\right)
$$

\section{RESULTS AND DISCUSSION}

\section{LCC Characterization}

The lignin/hemicellulose ratio, charge density and weight average molar mass $\left(\mathrm{M}_{\mathrm{w}}\right)$ of LCC $80 / 20$, LCC $80 / 20$ HMW, LCC $40 / 60$, and lignosulphonate are shown in Table 1 . The polydispersity index (PDI) describes the heterogeneity of the size distribution and is reported with the molar mass values. Pullulan was used for the molar mass calibration because standards made of LCCs were not commercially available and pullulan has been used for the molar mass determination of similar water soluble LCC previously (Abbadessa et al., 2018). It should be noted that the chemical composition of pullulan differs significantly from the studied LCC, and hence the measured molar mass values are only estimates used for qualitative comparison of the size of the different polymers studied in this work and should not be taken as exact values. SEC chromatograms presented in Figure 2 visualize the molar mass distribution for the different samples and the pullulan standard with $106 \mathrm{kDa} \mathrm{M}_{\mathrm{w}}$.

The apparent $\mathrm{M}_{\mathrm{w}}$ of LCC $80 / 20 \mathrm{HMW}$ is four times higher than for LCC $80 / 20$ (Table 1). In the SEC chromatogram (Figure 2) it is observed that although the LCC 80/20 HMW peak has a bimodal shape indicating large polydispersity, the peak maximum has moved to a smaller retention volume. Thus, it can be concluded that the HMW sample was notably larger in size compared to the LCC 80/20, and these two samples could be used to study the effect of molecular weight on performance.

Comparing LCC 80/20 and LCC 40/60 in Figure 2, their peak maxima and shapes are both similar, indicating that their molar masses are close. These samples had different lignin/ hemicellulose ratios and charge densities. LCC 80/20 had significantly higher lignin content, while for the LCC 40/60, the hemicellulose content was higher; the lignin/hemicellulose ratios were $80 / 20$ and $40 / 60$, respectively. The charge densities of LCC $80 / 20$ and LCC $40 / 60$ were $-2.2 \mathrm{meq} / \mathrm{g}$ and $-0.3 \mathrm{meq} / \mathrm{g}$, respectively. The samples originated from different pulping processes and raw materials. LCC 80/20 was produced from the side stream of the Domsjö Fabriker mill that utilizes a mixture of Norway spruce and Scotch pine as the raw material, while LCC 40/60 was produced from a side stream of a Swedish pulp mill with only Norway spruce as the raw material. LCC $80 / 20$ was derived from dissolving pulp production, which is a chemical pulping process utilizing sulfite and bisulfite ions to digest the wood chips. In the Domsjö Fabriker process, a pre-hydrolysis step was included, utilizing sulphur dioxide and sodium hydroxide to form sodium bisulfite in low chemical concentrations and at a higher $\mathrm{pH}$ (4) than in the main cooking process. This caused sulphonation of the lignin as well as its dissolution. Due to the higher $\mathrm{pH}$, the hemicelluloses were not completely hydrolyzed and could be utilized. The sulphonate groups were the main contributors to the high negative charge of the polymer. LCC 40/60 was derived from the TMP process utilizing water and heat to soften the wood 
TABLE 2 | Hemicellulose content of LCC 80/20 analyzed by GC-FID.

\begin{tabular}{|c|c|c|c|c|c|}
\hline Substance & Amount (\%) & Substance & Amount (\%) & Substance & Amount (\%) \\
\hline Arabinose & 0.6 & Galactose & 3.9 & Galacturonic acid & 0.4 \\
\hline Rhamnose & 0.1 & Glucose & 2.4 & Glucuronic acid & 0.3 \\
\hline Xylose & 1.6 & Mannose & 7.8 & 4-O-methylglucuronic acid & 0.4 \\
\hline
\end{tabular}

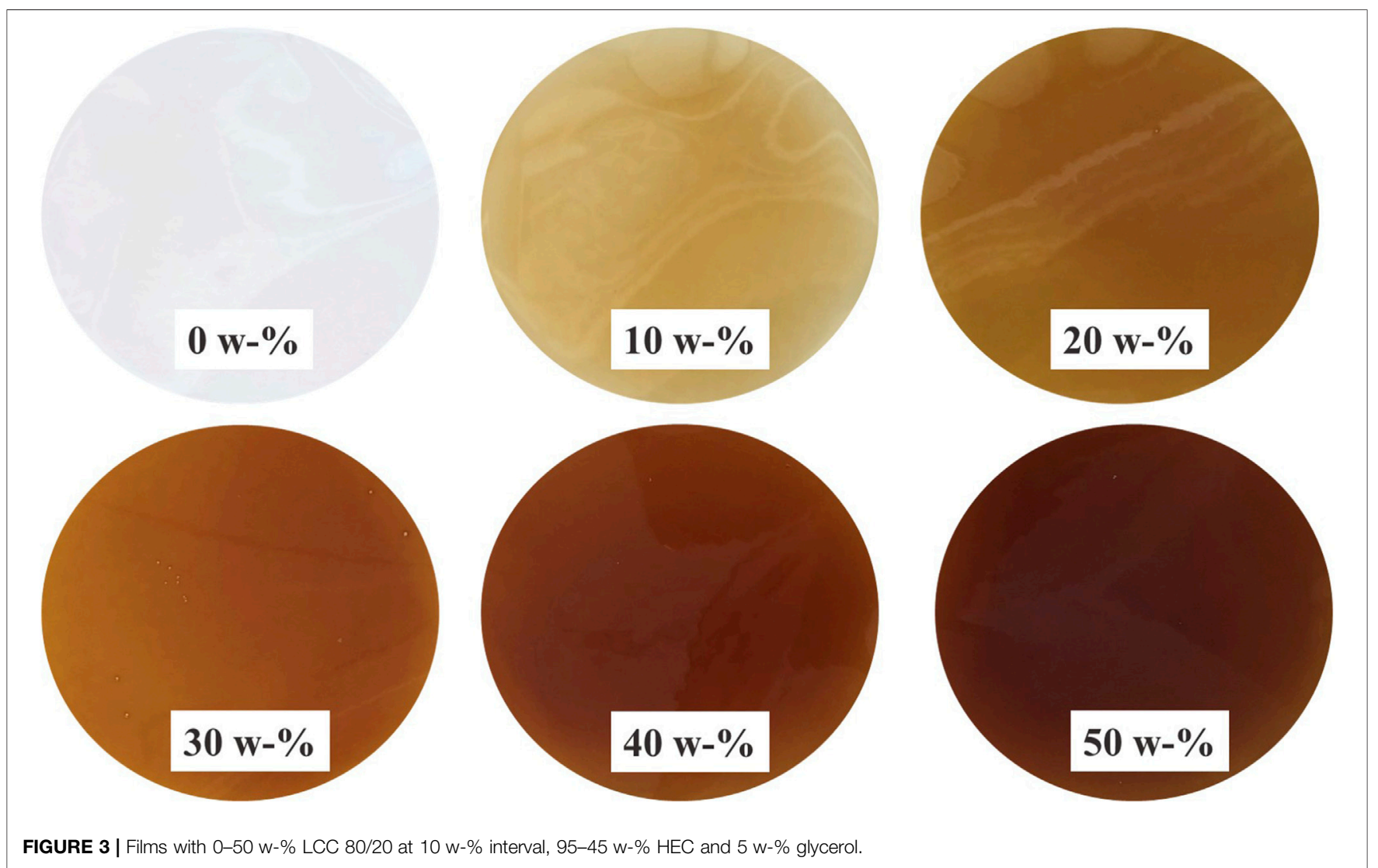

matrix and especially the lignin. The wood chips were then processed in mechanical refiners to separate the wood fibers into pulp. During this process, hemicelluloses and some bound and unbound lignin were dissolved in the side-stream liquors.

The lignosulphonate sample had substantially lower molecular weight than the LCC samples, although this sample also had a bimodal shape (Figure 2). Lignosulphonate contained no hemicellulose fraction, and its charge density $(-1.1 \mathrm{meq} / \mathrm{g})$ was in between the charge of LCC 80/20 and LCC40/60.

The hemicellulose fraction in LCC 80/20 consisted of varying sugar units (Table 2), mostly mannose, galactose, glucose and xylose. This result confirms the earlier observation (Oinonen 2014) that the LCC $80 / 20$ possess predominantly galactoglucomannan as the hemicellulose moiety.

\section{Visual Appearance of the Films}

Free-standing films of LCC 80/20 are shown in Figure 3. The glycerol content was held constant at $5 \mathrm{w}-\%$, the LCC content was varied between $0-50 \mathrm{w}-\%$ at $10 \mathrm{w}-\%$ intervals, and the remaining part (95-45 w-\%) was completed with HEC. The brown color in the films originated from the lignin fraction of LCCs.

LCC 80/20 with HEC and glycerol formed very smooth films without any visible irregularities, and similar films were achieved with LCC80/20 HMW, LCC 40/60, and lignosulphonate. This is well in line with previous confocal reflectance microscopy images of thin films from pure LCC 80/20 films showing that the LCCs form very smooth films without any visible precipitates (Borrega et al., 2020).

\section{Mechanical Properties of Composite Films}

Mechanical properties of the free-standing films containing varying amounts of LCC 80/20, LCC 80/20 HMW, LCC 40/ 60 , and lignosulphonate were characterized by measuring stressstrain curves (Figure 4). In the stress-strain experiment, the films are mechanically elongated until they break, which quantifies stress as a function of strain. During the measurement, the sample 


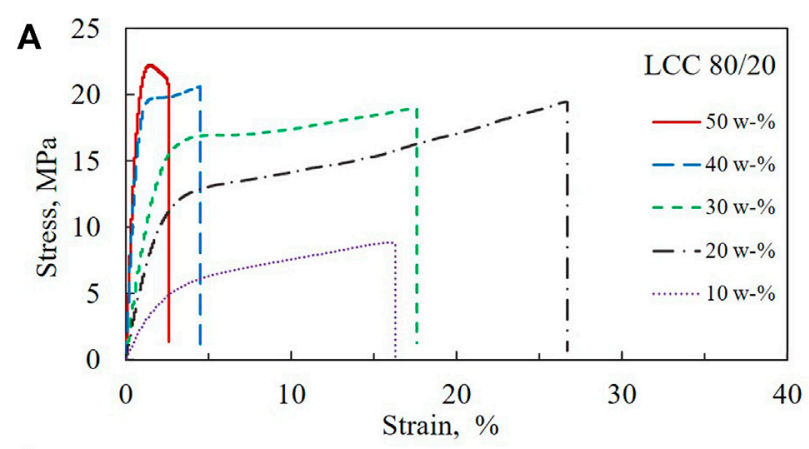

C

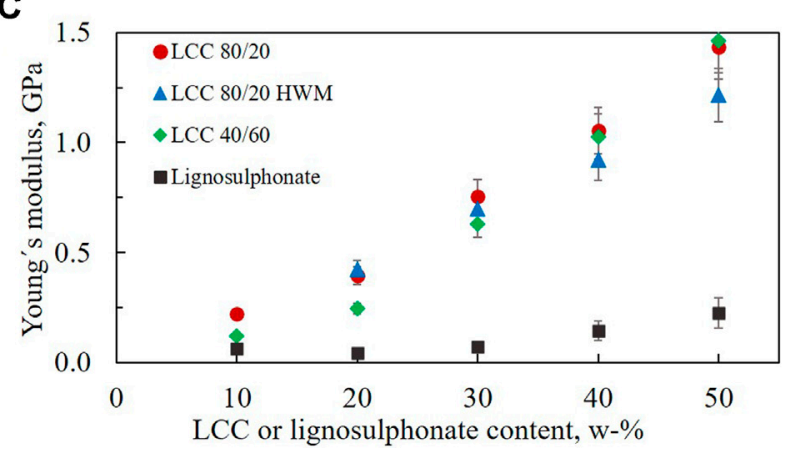

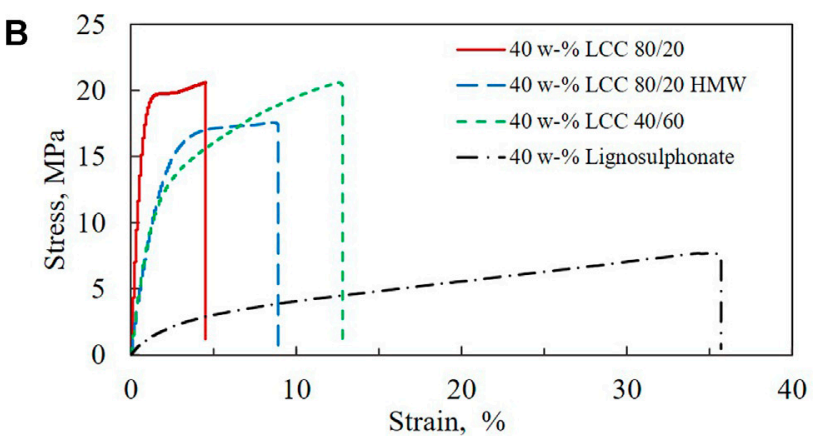

D

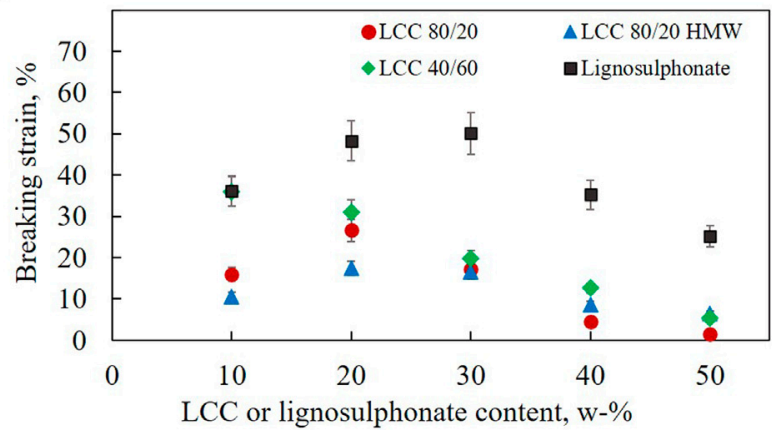

FIGURE 4 | Mechanical properties of free-standing HEC-based films containing LCCs or lignosulphonate. (A) Stress-strain curves for films containing 10-50 w-\% LCC 80/20. (B) Stress-strain curves for films containing 40 w-\% LCC or lignosulphonate. (C) Young's modulus of films as a function of LCC or lignosulphonate content. (D) Breaking strain of films as a function of LCC or lignosulphonate content. All films contained 5 w-\% glycerol and $85-45$ w- $\%$ HEC depending on LCC content.

absorbs energy by viscoelastic deformation as the polymer chains start to flow past one another until the sample fractures. The Young's modulus is obtained from the initial slope in the linear region of the stress-strain curve. It is defined as the material's ability for reversible elastic deformation, stiffness of the films in this case. The steeper the slope in the stress-strain curve, the higher the stress needed to generate deformation of material. The magnitude depends on interatomic energies per unit volume. The end of the linear region is called the yield point, after which plastic and at least partly irreversible deformation occurs. Finally, a break point is observed when the stress drops to zero. (Sperling et al., 2005; Youssefian et al., 2015; Tanzi et al., 2017).

Figure 4A shows representative stress-strain curves with varying LCC 80/20 content as an example of the effect of LCC concentration. The curves demonstrate how the Young's modulus increases as a function of concentration, seen as a steeper slope of the curve. The breaking strain decreases with increased concentration except for the film with $10 \mathrm{w}-\%$ LCC 80/ 20. Comparing the films containing $40 \mathrm{w}-\%$ LCC $80 / 20$ and LCC $40 / 60$ (Figure 4B), it can be observed that the linear region at the beginning of the curves is higher for LCC $80 / 20$, meaning that yield points are encountered at higher stress. This means that the maximum load the films withstood before irreversible deformation occurred was higher for LCC 80/20 compared to LCC $40 / 60$. When comparing the region after the yield point, it seems that, for LCC $80 / 20$, the elongation occurred at relatively constant stress, while for LCC 40/60, stress continued to increase with strain. A yield point followed by extensive elongation at almost constant stress is typical for tough plastic polymers. This type of elongation is called cold drawing which typically describes deformation where extensive chain orientation occurs (Sperling et al., 2005).

Comparing LCC $80 / 20,80 / 20 \mathrm{HMW}$, and LCC $40 / 60$ to lignosulphonate (Figure 4B), an even more pronounced difference is observed. The linear elastic region for lignosulphonate was significantly lower compared to the LCCs, and strain before breaking point was higher. This difference could be observed even during handling of the films. The films containing lignosulphonate appeared much softer with manual inspection.

Young's modulus was measured as a function of LCC and lignosulphonate content in the composite films (Figure 4C). All LCCs increased the Young's modulus of the composite films significantly, and the modulus increased with increasing LCC content. However, neither molar mass nor relative lignin/ hemicellulose ratio had any significant effect on Young's modulus. At $50 \mathrm{w}-\%$ LCC content, the Young's modulus of LCC 80/20 HMW was even slightly lower compared to the two other LCC samples. As Young's modulus is higher for a material that is more resistant to being stretched (Sperling et al., 2005), it was expected that the LCC 80/20 HMW would have demonstrated more entangled polymer chains causing larger Young's modulus. One reason for not observing this kind of behavior could be that the LCC 80/20 HMW might be 
more branched instead of having longer chains participating in the chain entanglement. However, since the three-dimensional structures of the LCCs are not known, this can only be hypothesized at this point. Comparing the results of the LCCs to lignosulphonate, it was observed that lignosulphonate did not increase the Young's modulus of the composite films significantly. This may be due to the smaller molar mass of the lignosulphonate polymer compared to the LCC samples or due to the lack of hemicelluloses in the lignosulphonate.

Youssefian and Rahbar (2015) have used atomistic simulations to study Young's modulus and energy densities of hydrogen bonds in hemicelluose, LCC and lignin in bamboo fibrils. The bamboo hemicellulose was xylan, and the lignin modelled in their work differs from the current study by being non-sulphonated. They found that, of the polymers studied, hemicellulose films had the highest Young's modulus due to having the highest energy density of hydrogen bonds. The second highest values were measured for LCC and lowest for lignin. Although the specific chemical structures of the materials studied in the present work differ from the former study, it can be assumed that the higher hemicellulose fraction in the LCC samples compared to the lignosulphonate increases the density of hydrogen bonds, contributing to higher Young's modulus values.

The ability of films to stretch before breaking is described by the breaking strain. An interesting finding was that increasing the concentration of LCC $80 / 20$, LCC $80 / 20$ HMW, and lignosulphonate from 10 to $20 \mathrm{w}-\%$ increased the breaking strain while increasing the concentration further to $30 \mathrm{w}-\%$ and above caused the strain to decrease (Figure 4D). For LCC 40/60, the strain constantly decreased as a function of increasing concentration from 10 to $50 \mathrm{w}-\%$. As the increase in strain at $20 \mathrm{w}-\%$ was not observed for LCC 40/60, which contained a higher fraction of hemicellulose than lignin, it is assumed that the non-linear correlation between strain and LCC or lignosulphonate content can be attributed to a higher lignin fraction in the LCC $80 / 20$, LCC $80 / 20 \mathrm{HMW}$, and lignosulphonate. Based on the results, it is concluded that viscoelastic properties of the composite films can be adjusted by optimizing the dosage of LCC. The ratio of lignin and hemicellulose in LCC seems to affect the strain properties of the films depending on polymer concentration. It is hypothesized that reason for the decrease in the breaking strain at $30 \%$ or higher dosage is the same for both LCC and lignosulphonate and would be due to more hydrogen bonding. Although the lignosulphonate is lacking the hemicellulose fraction, it is still able to form hydrogen bonds. Therefore, increasing the LCC or lignin concentration increased the number of attractive interactions in the films.

Breaking strain was clearly highest for the lignosulphonate sample (Figure 4D). This finding is consistent with previous findings by (Baumberger et al., 1996), who studied the effect of lignosulphonate concentration on starch composite films. The elongation at break was stated to increase owing to a plasticization effect of lignosulphonate. In the present work, the higher plasticizing effect of lignosulphonate compared to
LCC samples is probably due to both the chemical structure and the lower molar mass of lignosulphonate.

\section{Oxygen Permeability of LCC $80 / 20$ Composite Films}

As the LCC was found to enhance mechanical properties of polymeric films, it has the potential to be used in packaging applications. Renewable barrier films are an interesting area of research, and therefore, oxygen permeabilities of HEC-LCC composite films were studied. Since the molecular weight and lignin/hemicellulose ratio did not significantly affect Young's modulus of the films, and LCC $80 / 20$ showed the best mechanical properties (Figure 4B), only this sample was further used to evaluate oxygen permeability. Due to the softness and water sensitivity of lignosulphonate, that sample could be assumed to not perform well in OTR measurements.

The OTR was analyzed for the composite films containing 0-40 w-\% LCC 80/20, 95-55 w-\% HEC and $5 \mathrm{w}-\%$ glycerol. Measurements were performed at $23^{\circ} \mathrm{C}$, and 50 and $80 \%$ relative humidity (Figures $\mathbf{5 A}, \mathbf{B}$, respectively). The results demonstrate clearly that increasing the LCC 80/20 content decreased the oxygen transmission rate through the composite films at both the studied humidities.

There is a clear correlation between the OTR and Young's modulus of the films. The stiffer the film, the lower the oxygen transmission rate. Comparing the oxygen transmission rates of the films at $80 \% \mathrm{RH}$ to the results at $50 \% \mathrm{RH}$, a clear difference can be observed. At higher humidity, the oxygen transmission through the films was much higher, and the standard deviation between the measurements was also quite high for other samples except those containing 10 and $40 \mathrm{w}-\%$ of LCC 80/20.

To enable comparison to the literature, OTR values were normalized with the mean thickness of the films to estimate the oxygen permeability of the samples (Table 3 ). The thickness of the films was calculated as an average of three measurements per film, combining the results of films containing $10-50 \mathrm{w}-\%$ LCCs. On average, the thickness of LCC $80 / 20$ films was $70 \pm$ $5 \mu \mathrm{m}$. There was a small variation in the results describing deviation in the film preparation method by casting on a petri dish.

The increased oxygen permeability at higher humidity is assumed to be mostly caused by the hygroscopicity of the hydroxyethyl cellulose used in the composite films as a film-forming polymer. The sample containing $0 \mathrm{w}-\%$ LCC 80/20 contained $95 \mathrm{w}-\%$ HEC and $5 \mathrm{w}-\%$ glycerol. For this film, the OP at $50 \%$ RH was $0.3\left(\mathrm{~cm}^{3}\right.$ $\mathrm{mm}) /\left(\mathrm{m}^{2}\right.$ day atm $)$ and at $80 \% \mathrm{RH}$ it was $38\left(\mathrm{~cm}^{3} \mathrm{~mm}\right) /\left(\mathrm{m}^{2}\right.$ day atm). It can be concluded that HEC was not a suitable polymer to be used at high humidity in the composite films with LCC $80 / 20$ to achieve low oxygen permeability. However, despite using HEC with poor oxygen barrier properties, the effect of LCC 80/ 20 lowering the oxygen permeability is evident. The films containing $40 \%$ of LCC $80 / 20$ had 15 times lower OP at $50 \%$ RH and two times lower OP in $80 \% \mathrm{RH}$ compared to pure HEC films.

Wang et al. (2018) have classified barrier properties based on OP at $23^{\circ} \mathrm{C}$ and $50 \%$ or $0 \% \mathrm{RH}$. High barrier quality is achieved when the OP is between $0.04-0.4$, medium between $0.4-4$, low between $4-40$, 

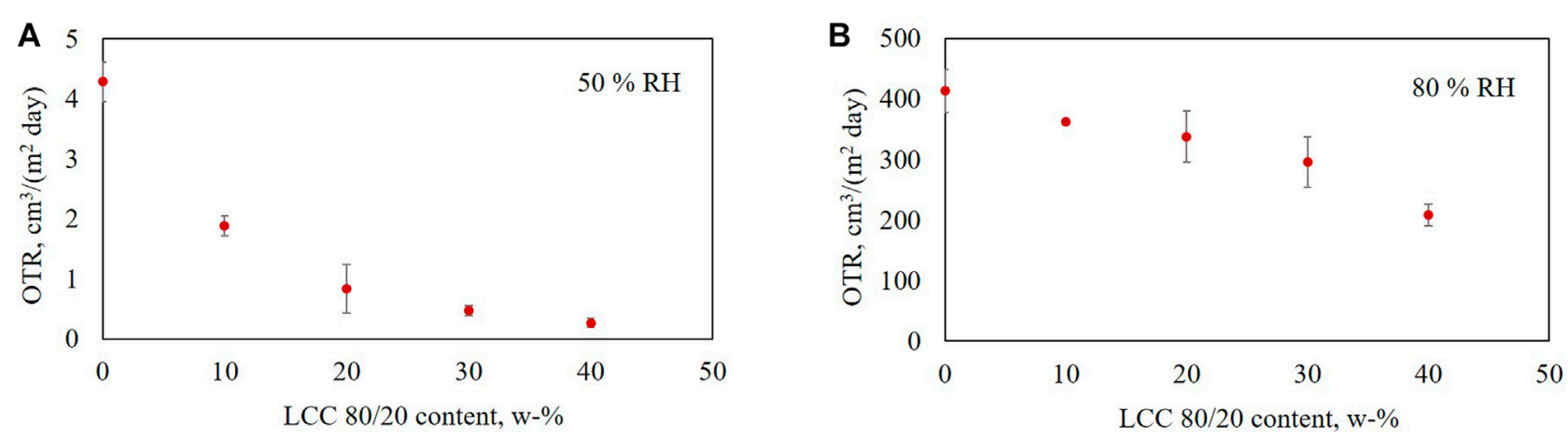

FIGURE 5| Oxygen transmission rate for films containing 0-40 w-\% LCC 80/20, 95-55 w- \% HEC and 5 w- $\%$ glycerol at 23 C and (A) 50\% and (B) 80\% humidity.

TABLE 3 | Oxygen permeability for LCC $80 / 20$ films at $23^{\circ} \mathrm{C}$ and 50 and $80 \%$ relative humidity.

\begin{tabular}{|c|c|c|}
\hline LCC 80/20 & $\begin{array}{c}\text { OP at } 50 \% \\
\mathrm{RH},\left(\mathrm{cm}^{3} \mathrm{~mm}\right) /\left(\mathrm{m}^{2}\right. \\
\text { day atm })\end{array}$ & $\begin{array}{c}\text { OP at } 80 \% \\
\mathrm{RH},\left(\mathrm{cm}^{3} \mathrm{~mm}\right) /\left(\mathrm{m}^{2}\right. \\
\text { day atm) }\end{array}$ \\
\hline $0 w-\%$ & 0.30 & 38 \\
\hline $10 w-\%$ & 0.13 & 35 \\
\hline $20 w-\%$ & 0.06 & 30 \\
\hline $30 w-\%$ & 0.03 & 27 \\
\hline $40 w-\%$ & 0.02 & 19 \\
\hline
\end{tabular}

and poor above $40\left(\mathrm{~cm}^{3} \mathrm{~mm}\right) /\left(\mathrm{m}^{2}\right.$ day atm). Comparing the OP results of the LCC composite films at 50\% RH (Table 3 ) to the values by Wang et al. (2018), two conclusions can be made: HEC film had a high oxygen barrier quality and increasing the LCC content in the composite films led to excellent performance as a function of LCC content. At $80 \%$ humidity, the barrier quality of all tested composite films was low. However, increasing the LCC content in the films significantly decreased oxygen permeability, even at $80 \% \mathrm{RH}$.

It is interesting to compare the results obtained herein with the oxygen permeability for various biopolymers and fossil-based alternatives reported previously (Lange et al., 2003; Aulin et al., 2010; Wang et al., 2018; Wu et al., 2021). However, there is a large variation between $\mathrm{OP}$ values for similar polymers depending on the raw material source and preparation of the films, which makes comparison challenging. For example, OP of nanocellulose films can vary between $0.02\left(\mathrm{~cm}^{3} \mathrm{~mm}\right) /\left(\mathrm{m}^{2}\right.$ day atm $)$ at $53 \% \mathrm{RH}$ (Österberg et al., 2013) to $0.58\left(\mathrm{~cm}^{3} \mathrm{~mm}\right) /\left(\mathrm{m}^{2}\right.$ day atm) at $50 \%$ RH (Rivière et al., 2021). For polypropylene, the variation might be $50-100\left(\mathrm{~cm}^{3} \mathrm{~mm}\right) /\left(\mathrm{m}^{2}\right.$ day atm $)$ at $0-90 \% \mathrm{RH}$ and for ethylene vinyl alcohol $0.001-0.01\left(\mathrm{~cm}^{3} \mathrm{~mm}\right) /\left(\mathrm{m}^{2}\right.$ day atm $)$ at 0\% RH (Wang et al., 2017). The best OP in the present work, $0.02\left(\mathrm{~cm}^{3} \mathrm{~mm}\right) /\left(\mathrm{m}^{2}\right.$ day atm $)$, was observed for the film containing $40 \mathrm{w}-\%$ LCC $80 / 20$ at $50 \%$ humidity. Compared to the values of cellulose nanofibril films, the result is similar to what was found in the work of Österberg et al. (2013) and significantly better compared to the CNF films studied in the work of Rivière et al. (2021). If the fragile nature of LCC $80 / 20$ films could be overcome by using alternative plasticizers, one could expect to achieve even better oxygen barrier properties with the LCC by increasing the concentration above $40 \mathrm{w}-\%$ in the freestanding films.

The effect of humidity has been studied also previously, and many researchers have found that increasing RH increases OP for hydrophilic polymers exponentially above a certain threshold. (Hong et al., 2005; Aulin et al., 2010; Österberg et al., 2013; Aguirre-Loredo et al., 2016; Blanchard et al., 2017; Wang et al., 2018; Wu et al., 2021; Zhu Rydberg et al., 2021) Plasticizing water molecules in the amorphous sections of the films are stated to reduce intermolecular interactions between polymer chains while increasing hydrogen bonding between polymer and water, reducing stiffness of the films. For example, Österberg et al. (2013) and Aulin et al. (2010) observed that oxygen transmission through fibrillated cellulose films increases sharply above $70 \% \mathrm{RH}$. Ethylene vinyl alcohol is reported to lose good oxygen barrier properties already above $60 \% \mathrm{RH}$ ( $\mathrm{Wu}$ et al., 2021).

Oxygen permeability depends on diffusion and solubility, and there are several explanations for the effect of relative humidity. At low $\mathrm{RH}$, the intermolecular interactions, such as hydrogen bonding and Van der Waals attraction, enable compact packing and a high cohesive energy density of the polymeric films. This lowers free volume and mobility of the polymer chains, decreasing gas permeability. Increasing water content in the films induces higher oxygen solubility (Aulin et al., 2010; Blanchard et al., 2017; Wang et al., 2018). The LCC studied in the present work is a hydrophilic polymer able to form intra- and intermolecular hydrogen bonds, which is assumed to contribute to the superior barrier properties of the LCC films at $50 \% \mathrm{RH}$.

Increasing LCC content in the films was demonstrated not only to enhance mechanical properties but also to decrease oxygen permeability of the films as a function of concentration. These results support the potential use of LCCs, for example, in oxygen barrier applications in the packaging industry. Since HEC is very susceptible to losing gas barrier performance at elevated $\mathrm{RH}$, alternative biopolymers will be studied in the composite films as a film forming polymer in the future. 


\section{CONCLUSION}

In this paper, we present a study of free-standing composite films to demonstrate the feasibility of a specific lignin-carbohydrate complex (LCC) for polymeric film applications. LCC samples with varying molecular weight and lignin/hemicellulose ratio were compared to lignosulphonate analyzing mechanical properties of the films. We observed that increasing LCC content increased Young's modulus of the composite films while the pure lignosulphonate did not have a significant effect. The LCC with higher lignin content withstood higher load. The increased Young's modulus of LCC films was speculated to originate from the higher energy density of hydrogen bonds facilitated mainly by the hemicellulose fraction in the polymer. The breaking strain had a non-linear correlation with concentration for the samples with high content of sulphonated lignin. The highest breaking strain was found for the lignosulphonate polymer. Oxygen permeabilities were analyzed at 50 and $80 \%$ relative humidity for the LCC sample demonstrating the best mechanical properties. Oxygen permeability decreased significantly with increasing LCC content in both humidities.

For future studies, a more comprehensive examination of the interactions of LCC with other film-forming polymers and plasticizers is recommended to find the optimal composition for specific types of applications. The enhanced mechanical properties and ability to decrease oxygen permeability of the composite films presented in this work indicate that LCC has potential in applications where polymeric films are used, such as barrier films in paper and board packaging. Hence it would be interesting to study the interactions of LCC with cellulose fibers in more detail. The LCC polymers could be used to enhance

\section{REFERENCES}

Abbadessa, A., Oinonen, P., and Henriksson, G. (2018). Characterization of Two Novel Bio-Based Materials from Pulping Process Side Streams: Ecohelix and CleanFlow Black Lignin. Bioresources 13 (4), 7606-7627. doi:10.15376/ biores.13.4.7606-7627

Aguirre-Loredo, R. Y., Rodríguez-Hernández, A. I., Morales-Sánchez, E., GómezAldapa, C. A., and Velazquez, G. (2016). Effect of Equilibrium Moisture Content on Barrier, Mechanical and thermal Properties of Chitosan Films. Food Chem. 196, 560-566. doi:10.1016/j.foodchem.2015.09.065

ASTM D3985-05 (2005). Standard Test Method for Oxygen Gas Transmission Rate through Plastic Film and Sheeting Using a Coulometric Sensor. West Conshohocken, PA: ASTM International.

Aulin, C., Gällstedt, M., and Lindström, T. (2010). Oxygen and Oil Barrier Properties of Microfibrillated Cellulose Films and Coatings. Cellulose 17 (3), 559-574. doi:10.1007/s10570-009-9393-y

Balakshin, M., Capanema, E., Gracz, H., Chang, H.-m., and Jameel, H. (2011). Quantification of Lignin-Carbohydrate Linkages with High-Resolution NMR Spectroscopy. Planta 233 (6), 1097-1110. doi:10.1007/s00425-011-1359-2

Baumberger, S., Lapierre, C., Monties, B., Lourdin, D., and Colonna, P. (1997). Preparation and Properties of Thermally Moulded and Cast LignosulfonatesStarch Blends. Ind. Crops Prod. 6 (3), 253-258. doi:10.1016/S0926-6690(97) 00015-0

Blanchard, A., Gouanvé, F., and Espuche, E. (2017). Effect of Humidity on Mechanical, thermal and Barrier Properties of EVOH Films. J. Membr. Sci. 540, 1-9. doi:10.1016/j.memsci.2017.06.031

Borrega, M., Päärnilä, S., Greca, L. G., Jääskeläinen, A.-S., Ohra-aho, T., Rojas, O. J., et al. (2020). Morphological and Wettability Properties of Thin Coating Films properties of the final products while simultaneously enabling more holistic and sustainable use of biomass.

\section{DATA AVAILABILITY STATEMENT}

The original contributions presented in the study are included in the article/Supplementary Material. Raw data is available upon request from corresponding authors.

\section{AUTHOR CONTRIBUTIONS}

BA designed and conducted experiments and interpret the data with input from A-SJ and MÖ. HK designed, supervised and interpreted the OTR measurements at high humidity. PO wrote about the LCC production by demonstration scale unit and provided the samples. The manuscript was otherwise written by BA with contributions from all authors. All authors have given approval to the final version of the manuscript.

\section{FUNDING}

This document is part of a project that has received funding from the Bio Based Industries Joint Undertaking (JU) under the European Union's Horizon 2020 research and innovation programme under grant agreement No. 837866. The JU receives support from the European Union's Horizon 2020 research and innovation programme and the Bio Based Industries Consortium.

Produced from Technical Lignins. Langmuir 36 (33), 9675-9684. doi:10.1021/ acs.langmuir.0c00826

Carvalho, D. M. d., Lahtinen, M. H., Lawoko, M., and Mikkonen, K. S. (2020). Enrichment and Identification of Lignin-Carbohydrate Complexes in Softwood Extract. ACS Sustainable Chem. Eng. 8 (31), 11795-11804. doi:10.1021/ acssuschemeng.0c03988

Dong, H., Zheng, L., Yu, P., Jiang, Q., Wu, Y., Huang, C., et al. (2020) Characterization and Application of Lignin-Carbohydrate Complexes from Lignocellulosic Materials as Antioxidants for Scavenging In Vitro and In Vivo Reactive Oxygen Species. ACS Sustainable Chem. Eng. 8 (1), 256-266. doi:10.1021/acssuschemeng.9b05290

Giummarella, N., Balakshin, M., Koutaniemi, S., Kärkönen, A., and Lawoko, M. (2019). Nativity of Lignin Carbohydrate Bonds Substantiated by Biomimetic Synthesis. J. Exp. Bot. 70 (20), 5591-5601. doi:10.1093/jxb/erz324

Giummarella, N., Pu, Y., Ragauskas, A. J., and Lawoko, M. (2019). A Critical Review on the Analysis of Lignin Carbohydrate Bonds. Green. Chem. 21 (7), 1573-1595. doi:10.1039/c8gc03606c

Henriksson, G., Areskogh, D., and Oinonen, P. A. (2012). Method to Increase the Molecular Weight of wood Mannans and Xylans Comprising Aromatic Moieties. European Patent Office, Patent WO 2012/071004 Al.

Henriksson, G., Lawoko, M., Martin, M. E. E., and Gellerstedt, G. (2007). Lignincarbohydrate Network in wood and Pulps: A Determinant for Reactivity. Holzforschung 61 (6), 668-674. doi:10.1515/HF.2007.097

Hong, S.-I., and Krochta, J. M. (2006). Oxygen Barrier Performance of WheyProtein-Coated Plastic Films as Affected by Temperature, Relative Humidity, Base Film and Protein Type. J. Food Eng. 77, 739-745. doi:10.1016/ j.jfoodeng.2005.07.034

Lange, J., and Wyser, Y. (2003). Recent Innovations in Barrier Technologies for Plastic Packaging?a Review. Packag. Technol. Sci. 16 (4), 149-158. doi:10.1002/pts.621 
Lawoko, M., Henriksson, G., and Gellerstedt, G. (2005). Structural Differences between the Lignin-Carbohydrate Complexes Present in Wood and in Chemical Pulps. Biomacromolecules 6 (6), 3467-3473. doi:10.1021/bm058014q

Lin, S. Y. (1992). “Ultraviolet Spectrophotometry," in Methods in Lignin Chemistry. Editors S. Y. Lin and C. W. Dence (Berlin, Heidelberg: Springer), 217-232. doi:10.1007/978-3-642-74065-7_15

Oinonen, P. (2014). A Biomimicking Approach for Hemicellulose Processing. [Dissertation]. Sweden: KTH Royal Institute of Technology.

Oinonen, P., Areskogh, D., and Henriksson, G. (2013). Enzyme Catalyzed CrossLinking of spruce Galactoglucomannan Improves its Applicability in Barrier Films. Carbohydr. Polym. 95, 690-696. doi:10.1016/j.carbpol.2013.03.016

Oinonen, P., Zhang, L., Lawoko, M., and Henriksson, G. (2015). On the Formation of Lignin Polysaccharide Networks in Norway spruce. Phytochemistry 111, 177-184. doi:10.1016/j.phytochem.2014.10.027

Österberg, M., Vartiainen, J., Lucenius, J., Hippi, U., Seppälä, J., Serimaa, R., et al. (2013). A Fast Method to Produce strong NFC Films as a Platform for Barrier and Functional Materials. ACS Appl. Mater. Inter. 5 (11), 4640-4647. doi:10.1021/am401046x

Pei, W., Chen, Z. S., Chan, H. Y. E., Zheng, L., Liang, C., and Huang, C. (2020). Isolation and Identification of a Novel Anti-protein Aggregation Activity of Lignin-Carbohydrate Complex from Chionanthus Retusus Leaves. Front. Bioeng. Biotechnol. 8, 1112. doi:10.3389/fbioe.2020.573991

Rivière, G. N., Pion, F., Farooq, M., Sipponen, M. H., Koivula, H., Jayabalan, T., et al. (2021). Toward Waste Valorization by Converting Bioethanol Production Residues into Nanoparticles and Nanocomposite Films. Sustainable Mater. Tech. 28, e00269. doi:10.1016/j.susmat.2021.e00269

Sperling, L. (2005). Introduction to Physical Polymer Science. Incorporated, Hoboken: John Wiley \& Sons.

Steinmetz, V., Villain-Gambier, M., Klem, A., Gambier, F., Dumarcay, S., and Trebouet, D. (2019). Unveiling TMP Process Water Potential as an Industrial Sourcing of Valuable Lignin-Carbohydrate Complexes toward Zero-Waste Biorefineries. ACS Sustainable Chem. Eng. 7 (6), 6390-6400. doi:10.1021/ acssuschemeng.9b00181

Strassberger, Z., Tanase, S., and Rothenberg, G. (2014). The Pros and Cons of Lignin Valorisation in an Integrated Biorefinery. RSC Adv. 4 (48), 25310-25318. doi:10.1039/c4ra04747h

Sundheq, A., Sundherg, K., Lillandt, C., and Holmhom, B. (1996). Determination of Hemicelluloses and Pectins in wood and Pulp Fibres by Acid Methanolysis and Gas Chromatography. Nordic Pulp Paper Res. J. 11, 216-219. doi:10.3183/ npprj-1996-11-04-p216-219

Tanzi, M., and Farè, S. (2017). Characterization of Polymeric Biomaterials. Cambridge: Elsevier Science \& Technology.

Wang, J., Gardner, D. J., Stark, N. M., Bousfield, D. W., Tajvidi, M., and Cai, Z. (2018). Moisture and Oxygen Barrier Properties of Cellulose Nanomaterial-
Based Films. ACS Sustainable Chem. Eng. 6 (1), 49-70. doi:10.1021/ acssuschemeng.7b03523

Wang, L., Lagerquist, L., Zhang, Y., Koppolu, R., Tirri, T., Sulaeva, I., et al. (2020). Tailored Thermosetting Wood Adhesive Based on Well-Defined Hardwood Lignin Fractions. ACS Sustainable Chem. Eng. 8, 13517-13526. doi:10.1021/ acssuschemeng.0c05408

Wu, F., Misra, M., and Mohanty, A. K. (2021). Challenges and New Opportunities on Barrier Performance of Biodegradable Polymers for Sustainable Packaging. Prog. Polym. Sci. 117, 101395. doi:10.1016/j.progpolymsci.2021.101395

Youssefian, S., and Rahbar, N. (2015). Molecular Origin of Strength and Stiffness in Bamboo Fibrils. Sci. Rep. 5, 11116. doi:10.1038/srep11116

Yuan, T.-Q., Xu, F., and Sun, R.-C. (2013). Role of Lignin in a Biorefinery: Separation Characterization and Valorization. J. Chem. Technol. Biotechnol. 88, 346-352. doi:10.1002/jctb.3996

Zhang, F., Lan, X., Peng, H., Hu, X., and Zhao, Q. (2020). A "Trojan Horse" Camouflage Strategy for High-Performance Cellulose Paper and Separators. Adv. Funct. Mater. 30 (32), 2002169. doi:10.1002/adfm.202002169

Zhao, Y., Shakeel, U., Saif Ur Rehman, M., Li, H., Xu, X., and Xu, J. (2020). Lignincarbohydrate Complexes (LCCs) and its Role in Biorefinery. J. Clean. Prod. 253, 120076. doi:10.1016/j.jclepro.2020.120076

Zhu Ryberg, Y. Z., Albertsson, A.-C., and Albertsson, A. (2011). Conceptual Approach to Renewable Barrier Film Design Based on wood Hydrolysate. Biomacromolecules 12 (4), 1355-1362. doi:10.1021/bm200128s

Conflict of Interest: Authors BA and A-SJ were employed by the company Kemira Oyj. Author PO was employed by the company Ecohelix AB.

The remaining authors declare that the research was conducted in the absence of any commercial or financial relationships that could be construed as a potential conflict of interest.

Publisher's Note: All claims expressed in this article are solely those of the authors and do not necessarily represent those of their affiliated organizations, or those of the publisher, the editors and the reviewers. Any product that may be evaluated in this article, or claim that may be made by its manufacturer, is not guaranteed or endorsed by the publisher.

Copyright (C) 2021 Asikanius, Jääskeläinen, Koivula, Oinonen and Österberg. This is an open-access article distributed under the terms of the Creative Commons Attribution License (CC BY). The use, distribution or reproduction in other forums is permitted, provided the original author(s) and the copyright owner(s) are credited and that the original publication in this journal is cited, in accordance with accepted academic practice. No use, distribution or reproduction is permitted which does not comply with these terms. 